\title{
ANTICORPOS NEUTRALIZANTES CONTRA RUBEOLA NUM GRUPO DE GESTANTES DE SÃO PAULO (1)
}

\begin{abstract}
Determinou-se os niveis de anticorpos neutralizantes contra rubéola em ry8 soros de igual número de pacientes que frequientam o ambulatório da Casa Maternal Leonor Mendes de Barros. Destas 778 mulheres, 600 (77,12\%) apresentavam níveis de anticorpos iguais ou superiores a 4 (diluição 1:4). Em relação à idade, o grupo examinado, com uma idade média de 25,6 anos, permite verificar que no grupo etário de 15 a 19 anos a frequiência de pacientes com anticorpos na diluiça $1: 4$ ou maior é de $79,43 \%$; no grupo de 20 a 24 anos, $75,69 \%$; no de 25 a $29,77,38 \%$; de 30 a 34, 82,50\%; de 35 a $39,75,68 \%$ e de 40 a 44, $50.00 \%$. A comparação dos resultados obtidos em cada grupo etário da amostra examinada, mostra que os percentuais de positividade das idades compreendidas entre 15 e 39 anos são muito próximas, sendo que o grupo de 40 a 44 anos apresenta um percentual notadamente menor de pacientes com anticorpos. Esta discordância demonstrou-se estatisticamente significativa ao nivel de 0,01 . No que se refere à côr, das 350 gestantes de côr branca, 79,14\% apresentaram anticorpos nos niveis mencionados anteriormente; das 90 pacientes de côr preta, $75,56 \%$; das 317 mulheres grávidas de côr parda, 75,71\% e das 21 gestantes de côr amarela, $71,43 \%$ possuiam niveis de anticorpos. Para inquéritos sôro-epidemiológicos de larga escala, a prova de neutralizacão apresenta inconvenientes de ordem prática pelo que se fau necessário estudar mais amplamente a correlação dos resultados desta técnica com aquêles fornecidos por outros, entre as quais se destaca, sem dúvida, a reação de inibição da hemaglutinacão.
\end{abstract}

\section{N T RODUÇ A}

Depois de mais de um século de relativa escuridão sôbre esta doença transmissível da infância e adolescência, ela adquiriu uma nova preeminência nos primórdios da Segunda Grande Guerra, após as observaçōes de Gregg em 1941 (Weller \& NeVA ${ }^{28}, 1965$ ), apresentando correlação entre a catarata observada em 78 crianças e a infeç̧ão pelo vírus da rubéola das mães no primeiro trimestre de gravidez. Êste nôvo aspecto da rubéola trouxe uma mudança permanente de atitude por parte dos médicos e do povo em geral. A maioria dos ca- sos, especialmente entre crianças, provàvelmente nunca recorreu à assistência médica, falseando em conseqüência, os estudos sôbre tendência de morbidade e distribuição.

Além de serem as epidemias de rubéola fator de alteração nas populações escolares e militares, esta doença é uma das poucas entre as ocasionadas por vírus, que apresentam efeito teratogênico sôbre o feto, o que ocorre quando a rubéola atinge a paciente no primeiro trimestre da gestação. A rubéola materna no primeiro trimestre da gravidez traz

(1) Da Cadeira de Mícrobiologia Aplicada da Faculdade de Higiene e Saúde Pública da USP. - Resumo da Tese de Doutoramen to, apresentada à Faculdade de Farmácia e Bioquimica da USP, em 20-12-1967. 
COTILlo Z., L. G. - Anticorpos neutralizantes contra rubéola num grupo de gestantes de Sāo Paulo. Rev. Saúde públ., 2(1):29-43, jun. 1968.

consigo $18 \%$ a $19 \%$ de probabilidade de provocar malformações congênitas.

A importância cada vez maior que a rubéola está alcançando entre as doenças de etiologia viral, nos leva, neste primeiro trabalho, a determinar o nível médio de anticorpos neutralizantes contra ruhéola, a fim de conhecer a incidência da doença, assim como a sua distribuição, escolhendo para tanto o grupo no qual a doença manifesta a sua total periculosidade, as gestantes.

O emprêgo da técnica de sôro-neutralização, para a determinação do nível de anticorpos, embora seja uma técnica muito demorada (requer 7 dias para se fazer a leitura final) e demande enorme gasto de material, pessoal e tempo, parecęu-nos o mais apropriado uma vez que as reaçôes recentemente descritas, entre as quais sem dúvida se destaca a de inibição da hemaglutinação, carecem de estudos comparativos.

Neste trabalho, portanto, descreveremos os resultados conseguidos através da prova de neutralização, embora continuemos as nossas experiências com as outras técnicas.

\section{MATERIAL E MÉTODOS}

Coleta de soros - Os soros foram obtidos de mulheres grávidas que freqüentam o ambulatório da Casa Maternal Leonor Mendes de Barros. A amostragem, feita com a ajuda do Departamento de Estatística Aplicada da Faculdade de Higiene e Saúde Pública, assinalou por meio de sorteio, empregando a tabela de números casuais, 15 dias do mês de maio, dias nos quais se ohteve mais ou menos $10 \mathrm{ml}$ de sangue de tôdas as grávidas que compareceram ao hospital. Cada uma destas pacientes foi submetida a uma única sangria, conseguindo-se um total de 784 amostras.

$O$ s soros obtidos destas sangrias foram todos guardados, sem serem inativados, no congelador a $-20^{\circ} \mathrm{C}$ até o momento da prova.
Cultura de células -... As células RK-13, linhagem de células de rim de coelho, foram inicialmente obtidas do Instituto Adolfo Lutz e submetidas a 30 repiques no Laboratório de Virologia do Departamento de Microbiologia e Imunologia Aplicadas da Faculdade de Higiene e Saúde Pública, antes de se iniciar a realização das provas de sôro-neutralização.

Para a cultura destas células usou-se como meio de crescimento o meio de Eagle com $15 \%$ de sôro de vitelo, sôro prèviamente inativado a $56^{\circ} \mathrm{C}$ por $30 \mathrm{mi}$ nutos, e as tripsinizações para subculturas foram realizadas com a mistura de tripsina a $0,2 \%$ mais versene a $0,02 \%$.

Com a finalidade de preparar as culturas de células em tubos, necessárias para a realização das provas de sôro-neutralização, foram preparadas culturas em garrafas de Roux, semanalmente. As garrafas eram incubadas a $37^{\circ} \mathrm{C}$, durante 7 dias, ao fim dos quais eram submetidas à tripsinização da maneira descrita acima. Cada garrafa de Roux proporcionava aproximadamente de 120 a 150 tubos contendo 200.000 células por ml. Os tubos assim preparados eram incubados em posição estacionária até atingir confluência total (em geral do terceiro ao quinto dia), após o que se procedia à troca do meio de crescimento para o meio de manutenção, que consistia de meio de Eagle (LeErhoy ${ }^{11}$, 1966) com $2 \%$ de sôro de galinha (Parkman et alii $\left.{ }^{15}, 1964\right)$, prèviamente inativado a $56^{\circ} \mathrm{C}$ por 30 minutos. Esta troca de meio foi sempre efetuada no dia anterior ao da inoculação, nos tubos com as culturas de células, com a finalidade de se verificar a ausência de contaminação nos mesmos.

Virus da rubéola - $\mathrm{O}$ vírus da rubéola usado no presente estudo foi a amostra gentilmente enviada pelo Dr. J. A. Dudgeon, correspondente à cepa denominada "West Point", com número de referência RVRB-21, tendo sido submetida a 16 passagens em RK-13, antes de chegar ao nosso Laboratório e com um 
COTILlO Z., L. G. - Anticorpos neutralizantes contra rubéola num grupo de gestantes de São Paulo. Rev. Saúde públ., 2(1):29-43, jun. 1968.

título de $10^{3, \tilde{5}}$ DICT $_{\tilde{5} 0}$ por $\mathrm{ml}$. Esta amostra foi sub-cultivada quatro vêzes na linhagem de células utilizadas neste trabalho, atingindo após êste período títulos que oscilaram entre $10^{4,0}$ e $10^{4,3}$ DICT $_{50}$ por $\mathrm{ml}$.

Soros hiperimunes contra rubéola -.. Foram igualmente remetidos pelo Dr. J. A. Dudgeon uma amostra de sôro hiperimune de coelho, com número de referência $R 3 / 66$ e com um título neutralizante maior que $1 / 16$ e um "pool" de soros de convalescentes de rubéola com um título neutralizante de $1 / 128$.

Prova de neutralização - A prova de neutralização foi realizada empregando-se diluições seriadas dos soros e dose constante de vírus. Embora Parkman et alii ${ }^{15}$ (1964) tenham descrito alteraçōes nos níveis de anticorpos segundo as diferentes doses de vírus a serem empregadas, foi fixada a alíquota de vírus contendo 100 DICT $_{50}$, determinada por titulação prévia, segundo as recomendações de McCarthy, Taylor-Robinson \& PilLinger $^{1: 2}$ (1963); Dudgeon, Butler \& Plotkin ${ }^{4}$ (1964) e Hutchinson \& Thompson $^{8}$ (1965). As diluições dos soros realizaram-se em meio basal de Eagle sem sôro e a diluição de vírus para atingir a concentração desejada efetuou-se em meio basal de Eagle com 1\% de albumina bovina (CHANG \& GEYER ${ }^{3}$, 1957 e Parkman et alii $\left.{ }^{15}, 1964\right)$.

Volumes iguais das diluições dos soros não inativados (McCARTHY, TAYLoRRobinson \& Pillinger ${ }^{12}$, 1963) e do vírus foram misturados $\mathrm{e}$ incubados a $37^{\circ} \mathrm{C}$ por uma hora, após o que conservaram as misturas na geladeira 2 horas antes da inoculação. Para cada uma das diluições dos soros, inocularam-se 2 tubos de $\mathrm{RK}_{13}$, que apresentavam confluência total e nos quais tinha sido colocado o meio de manutenção da maneira descrita acima. Cada tubo recebeu $0,2 \mathrm{ml}$ da mistura sôro-vírus. A incubação dos tubos inoculados realizou-se a $37^{\circ} \mathrm{C}$, em posição estacionária, realizan- do-se as leituras no terceiro, quinto e sétimo dia, ao microscópio com um aumento de 84 vêzes, à luz do dia, a fim de determinar o efeito citopático que apresentassem as células.

$O$ efeito citopático da cêpa do vírus da rubéola usada no presente trabalho é aquêle descrito por Dudgeon, Butler \& Plotkin $^{4}$ (1964), para o vírus adaptado a $R_{13}$. Segundo a descrição dêste autor, no terceiro dia as células dos extremos da camada celular sofrem um arredondamento, apresentando ao mesmo tempo focos que podem ser apreciados em tôda a extensão da camada. Por volta do quinto dia, aproximadamente, as culturas inoculadas apresentam muitos focos com grandes acúmulos de granulaçōes eosinófilas no citoplasma. No sétimo ou oitavo dia as áreas dêstes focos já se estenderam e a necrose celular apresenta-se avançada, aparecendo espaços livres de células na camada celular. Para a amostra empregada neste estudo o efeito citopático mostrando desintegração de mais de $50 \%$ das células foi conseguido entre o oitavo e nono dias, apresentando-se a completa desintegração da camada celular entre os $100^{\circ}$ e $12 .^{\circ}$ dias, como se pode observar nas fotografias apresentadas. (Figs. 1 e 2).

$O$ ponto final da titulação é dado pela mais alta diluição do sôro, que mostra uma proteção parcial das células inoculadas com a mistura sôro-vírus, ao fim de sete dias, sendo expresso o título de anticorpos presentes nesse sôro como a recíproca dessa diluição.

Aquêles soros que não mostravam inibição da replicação viral na diluição de $1 / 4$ foram considerados como desprovidos de anticorpos (Dudgeon, Butler \& Plotkin ${ }^{4}, 1964$ ).

As células normais, não inoculadas, apresentam uma disposição fechada de células poligonais, mostrando cada célula numerosos vacúolos e ocasionalmente encontrando-se células multinucleadas ou com grandes vacúolos. 
COTILLO Z., L. G. - Anticorpos neutralizantes contra rubéola num grupo de gestantes de São Paulo. Rev. Saúde públ., z(1):29-43, jun. 1968.

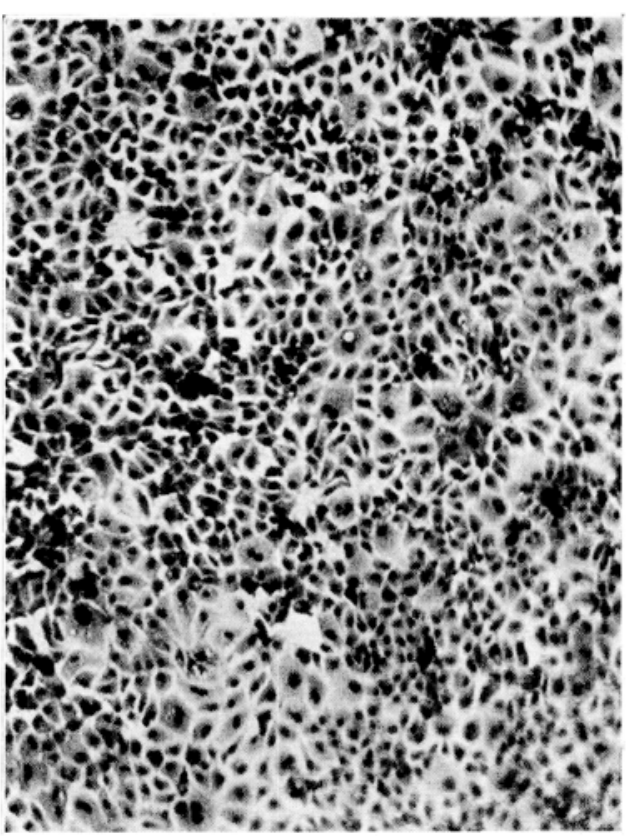

Fig. 1 - Células RK 13 não inoculadas (Contrôle). Nove dias de incubação a $37^{\circ} \mathrm{C}$. Coloração hematoxilina e eosina. $250 \times$.

Os contrôles realizados com cada uma das séries de soros foram os seguintes:

- Contrôle do vírus, inoculando 100 , 10,1 e $0,1 \quad D_{50}$ em $0,1 \mathrm{ml}$;

- Contrôle de neutralização positiva, sôro de convalescente de rubéola e sôro hiperimune de coelho;

- Contrôle da toxicidade dos soros, inoculando os soros diluídos a $1 / 4$.

\section{RESULTADOS}

Durante os dias em que foi realizada colheita de sangue das mulheres grávidas, que freqüentaram o Ambulatório da Casa Maternal Leonor Mendes de Barros, obtivemos 784 amostras, das quais foram eliminadas 6 , apresentando-se assim ùnicamente em tôdas as tabelas e gráficos os resultados de 778 soros.

Em se tratando de profissão, 700 $(89,3 \%)$ das gestantes manifestaram es-

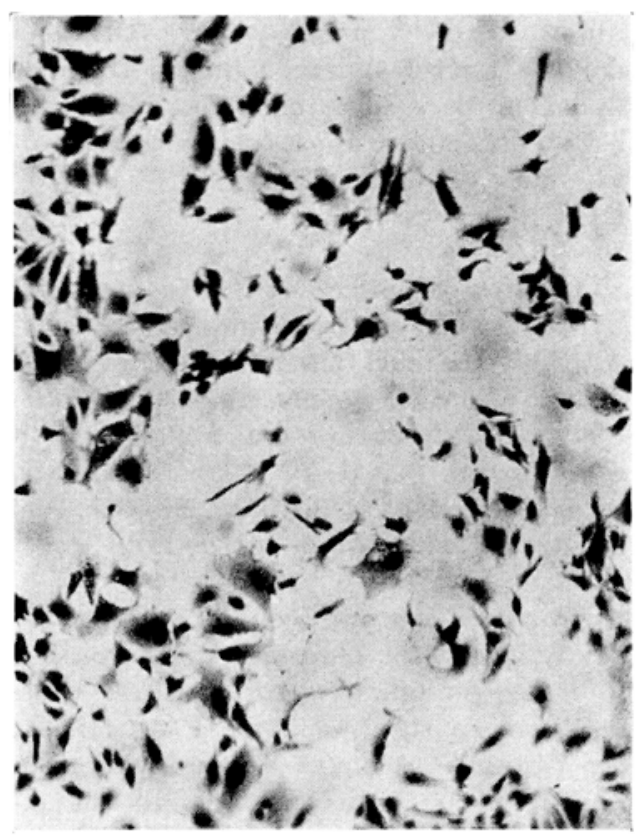

Fig. 2 - Efeito citopático do 9.0 dia nas células de RK 13 inoculadas com a cepa «West Point» de vírus da rubéola. Coloração hematoxilina e eosina. $250 \times$.

tarem entregues ùnicamente às obrigações de dona de casa, $70(8,9 \%)$ declararam serem empregadas domésticas, o que perfaz um total de $770(98,2 \%)$ e equivale à quase totalidade da amostra.

Esta predominância de mulheres dedicadas a uma única ocupação impede-nos de tentar correlacionar as atividades das pacientes integrantes dêste estudo com o nível de anticorpos neutralizantes contra rubéola. Todavia, segundo observaram Sever, Nélson \& Gilkeson ${ }^{20}$ (1965) ao estudarem os efeitos da epidemia de rubéola em 1964 nos Estados Unidos, as donas de casa apresentaram a mesma incidência de rubéola clínica que as mulheres dedicadas a outras atividades. Não vemos razões para que o mesmo fato não se apresente em nosso meio.

A dificuldade de determinar a veracidade das informações relativas ao estado civil, nos levou a não incluir êste item na avaliação da imunidade contra a ru. 
COTILLO Z., L. G. - Anticorpos neutralizantes contra rubéola num grupo de gestantes de São Paulo. Rev. Saúde públ., 2(1):29-43, jun. 1968.

béola. Ùnicamente com fins ilustrativos, consignamos que, das 778 gestantes integrantes de nosso estudo, $274 \cdot(35,22 \%)$ declararam serem solteiras, $495(63,63 \%)$, casadas e $9(1,16 \%)$ declararam outros estados civis.

Ao ser inquirida cada uma das mulheres grávidas sôbre se tinha tido ou não rubéola, a maioria não soube informar com certeza, existindo muitas que nunca tinham ouvido falar sôbre esta doença. Isto nos levou a deixar de lado as informações coletadas sôbre a história da rubéola nas gestantes que integraram a nossa amostra. Um fato que reafirma a procedência da nossa atitude é o referido por Sever, Schiff \& HuebNER ${ }^{21}$ (1964) que, ao estudarem a correlação entre o relato de rubéola anterior e a presença ou ausência de anticorpos neutralizantes, referem que de 176 mulheres que afirmaram ter tido rubéola, $150(85,2 \%)$ apresentavam anticorpos e $26(14,8 \%)$ não mostravam anticorpos. Das 288 grávidas que declara- ram não ter tido rubéola, $234,(81,25 \%)$ apresentavam anticorpos e $54(18,75 \%)$ não apresentavam anticorpos.

Desde que Green et alii 7 (1965) demonstraram que voluntários eram resistentes a infecções artificialmente induzidas com vírus da rubéola quando o nível de anticorpos neutralizantes contra rubéola no sôro era de pelo menos 4 (diluição $1: 4$ ), tomamos êste nível como determinativo da presença ou ausência de anticorpos.

Segundo êste critério, das 778 mulheres do nosso estudo, $600(77,12 \%)$ apresentavam anticorpos e $178(22,88 \%)$ denotavam ausência dos mesmos.

Das 600 que apresentavam anticorpos, $81,51 \%$ possuiam níveis que estavam entre as diluições $1: 4,1: 8$ e $1: 16$.

Das 600 que apresentavam anticorpos, $81,51 \%$ possuiam níveis que estavam entre as diluições $1: 4,1: 8$ e $1: 16$.

$\mathrm{Na}$ Tabela 1, onde apresentamos a distribuição das gestantes segundo a presença ou ausência de anticorpos em cada

T A B E L A 1

Distribuição percentual das gestantes com e sem anticorpos neutralizantes, segundo os grupos etários

\begin{tabular}{|c|c|c|c|c|c|}
\hline \multirow{3}{*}{$\begin{array}{c}\text { Idade } \\
\text { (Anos completos) }\end{array}$} & \multirow{3}{*}{ Total } & \multicolumn{4}{|c|}{ Título de anticorpos neutralizantes } \\
\hline & & \multicolumn{2}{|c|}{$<4(1)$} & \multicolumn{2}{|c|}{4 ou mais (2) } \\
\hline & & N.o & $\%$ & N.o & $\%$ \\
\hline $15-19$ & 141 & 29 & 20,57 & 112 & 79,43 \\
\hline $20-24$ & 255 & 62 & 24,31 & 193 & 75,69 \\
\hline $25-29$ & 168 & 38 & 22,62 & 130 & 77,38 \\
\hline $30-34$ & 120 & 21 & $\mathbf{1 7 , 5 0}$ & 99 & 82,50 \\
\hline $35-39$ & 74 & 18 & 24,32 & 56 & 75,68 \\
\hline $40-44$ & 20 & 10 & 50,00 & 10 & 50,00 \\
\hline Total & 778 & 178 & 22,88 & 600 & 77,12 \\
\hline
\end{tabular}

(1) Titulo $<4=$ Sem anticorpos neutralizantes.

(2) Titulo de 4 ou mais $=$ Com anticorpos neutralizantes. 
COTILLO Z., L. G. - Anticorpos neutralizantes contra rubeola num grupo de gestantes de São Paulo. Rev. Saúde públ., 2(1):29-43, jun. 1968.

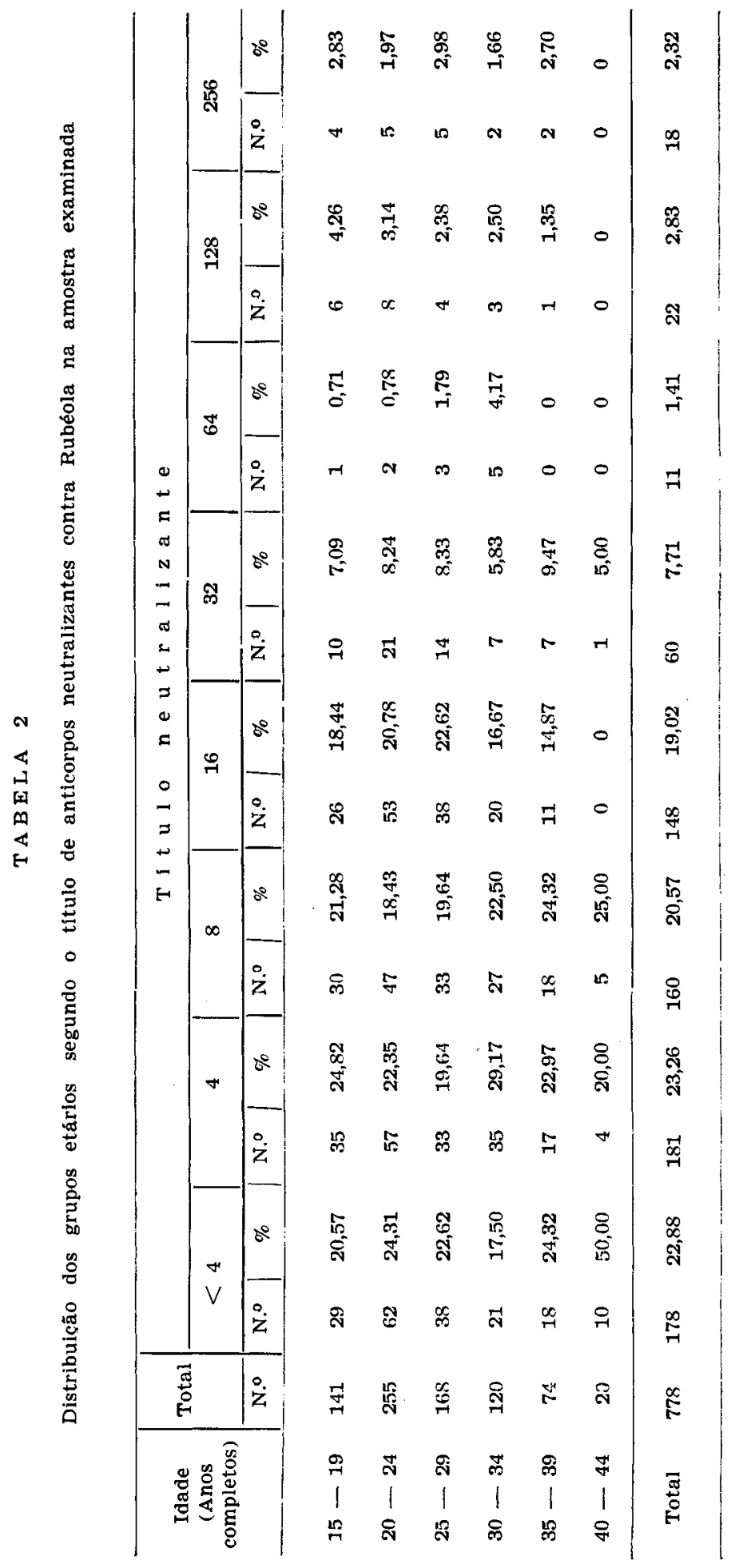


COTILLO Z., L. G. - Anticorpos neutralizantes contra rubéola num grupo de gestantes de São Paulo. Rev. Saúde públ., 2(1):29-43, jun. 1968.

grupo etário, pode-se verificar que a freqüência relativa apresenta pouca variação entre os 15 e 39 anos, mostrando um declínio acentuado no grupo etário de 40 a 44 anos.

$\mathrm{Na}$ Tabela 2 apresentamos a distribuição dos diversos níveis de anticorpos em cada um dos grupos etários da amostra examinada, assim como a distribuição daquelas que não apresentavam nível de anticorpos (título menor que 1:4).

Segundo se pode observar nesta tabela, em cada um dos grupos etários o percentual de indivíduos em cada nível de anticorpos vai decrescendo gradualmente, com pouquíssimas exceções, à medida que os títulos aumentam.

A Tabela 3 permite verificar, respectivamente, a distribuição das gestantes com e sem anticorpos em relação à côr e a distribuição das mulheres grávidas com anticorpos em relação à côr, podendo-se observar que $79,14 \%$ das brancas apresentam anticorpos neutralizantes conlra a rubéola. As gestantes pretas e pardas apresentam quase o mesmo percentual
$(75,56 \%$ e $75,71 \%$, respectivamente $)$ com anticorpos e nas de côr amarela se verifica que o percentual com título de anticorpos é ùnicamente $71,43 \%$.

A distribuição dos diversos títulos neutralizantes de anticorpos segundo a côr da gestante é apresentada na Tabela 4, onde se pode observar, para cada uma das côres consideradas, o mesmo declínio gradual da frequiência relativa a medida que os títulos de anticorpos vão aumentando, com exceção das pacientes de côr amarela, que apresentam resultados que não acompanham esta tendência.

\section{DISCUSAO}

A possibilidade de se determinar o nível de anticorpos contra a rubéola mediante um teste de reconhecida segurança, nos proporcionou a oportunidade de verificar a prevalência dos anticorpos neutralizantes contra rubéola num grupo populacional das mulheres grávidas que freqüentam a Casa Maternal Leonor Mendes de Barros.

TABELA 3

Distribuição das gestantes com e sem anticorpos em relação à côr

\begin{tabular}{|c|c|c|c|c|c|}
\hline \multirow{3}{*}{ Cô r } & \multirow{3}{*}{ Total } & \multicolumn{4}{|c|}{ Título de anticorpos neutralizantes } \\
\hline & & \multicolumn{2}{|c|}{$<4(1)$} & \multicolumn{2}{|c|}{$4(2)$} \\
\hline & & N.o & $\%$ & N.o & $\tilde{F}$ \\
\hline Branca & 350 & 73 & 20,86 & 277 & 79,14 \\
\hline Preta & 90 & 22 & 24,44 & 68 & $\mathbf{7 5 , 5 6}$ \\
\hline Parda & 317 & 77 & 24,29 & 240 & 75,71 \\
\hline Amarela & 21 & 6 & 28,57 & 15 & 71,43 \\
\hline Total & 778 & 178 & 22,88 & 600 & 77,12 \\
\hline
\end{tabular}

(1) Titulo $<4=$ Sem anticorpos neutralizantes.

(2) Titulo de 4 ou mais $=$ Com anticorpos neutralizantes. 
COTILLO Z., L. G. - Anticorpos neutralizantes contra rubéola num grupo de gestantes. de São Paulo. Rev. Saúde pübl., 2(1):29-43, jun. 1968.

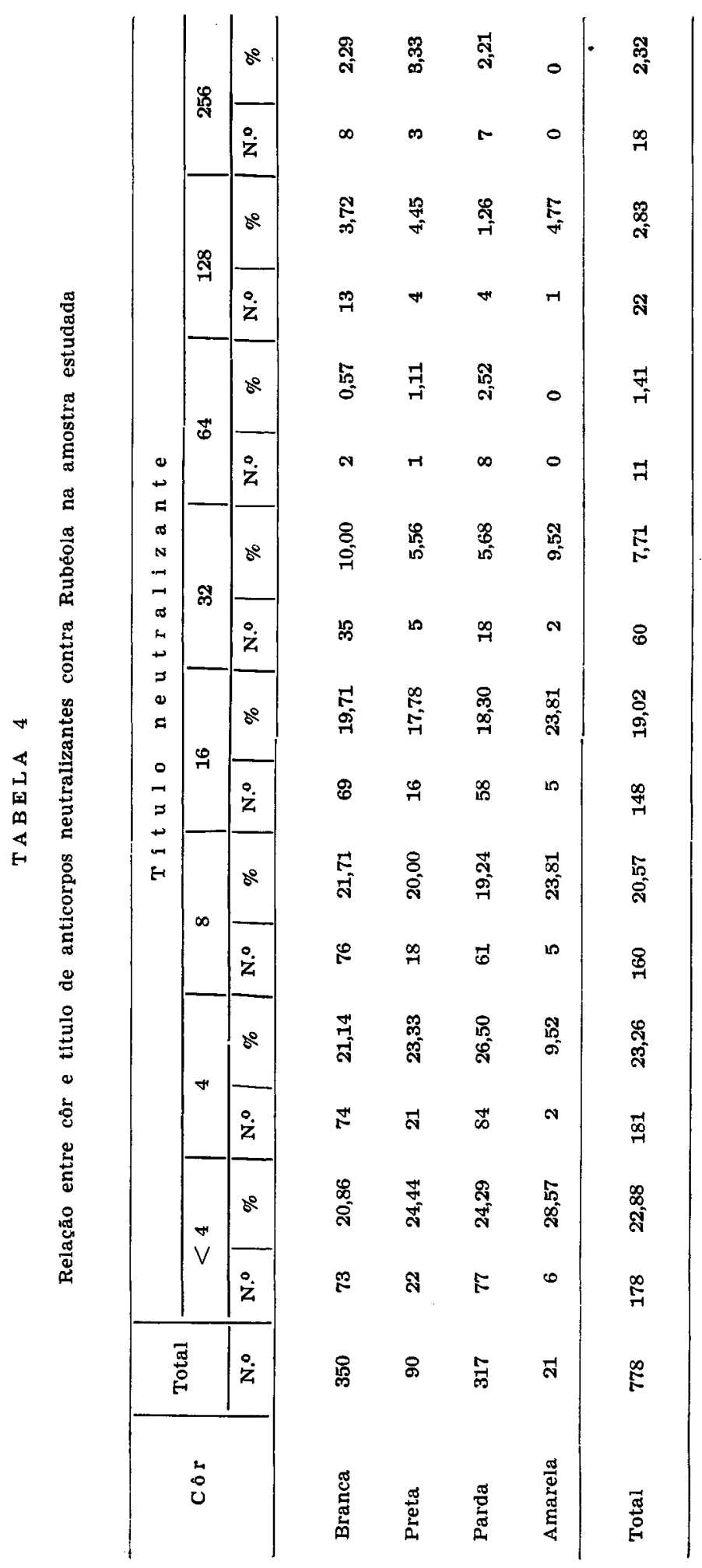


COTILLO Z., L. G. - Anticorpos neutralizantes contra rubéola num grupo de gestantes de São Paulo. Rev. Saúde públ., 2(1):29-43, jun. 1968.

A prova da sôro-neutralização, como método de determinação de nivel de an. ticorpos circulantes, é técnica das mais adequadas para esta finalidade, dada a sua reprodutibilidade quaindo realizada em condiçōes rigorosamente padronizadas e, frequientemente, em sistemas celulares que permitam a sua leitura através de efeito citopático.

Por outro lado, para inquéritos sorológicos de larga escala esta prova apresenta inconvenientes de ordem prática como o grande número de tubos de culturas de células a serem inoculadas (o que envolve preparo de meios de cultura e outras manobras próprias do processo de cultivo de células "in vitro") e a necessidade de se esperar pelo menos 7 dias para se obter os resultados. Faz-se necessário estudar com mais detalhes a correlação dos resultados obtidos com esta técnica com os apresentados por outros, entre os quais se destaca a reação de inibiçẩo da hemaglutinação recentemente descrita por Stewart et alii ${ }^{25}$ (1967).

A determinação dêstes anticorpos tem como principal objetivo estabelecer o grau de imunidade desta população e ao mesmo tempo avaliar os riscos a que se encontram expostas as gestantes que freqüentam êste hospital, quando no primeiro trimestre da gravidez, de contrair rubéola ao serem expostas a casos endê. micos, surtos esporádicos na comunidade ou mesmo a uma epidemia.

É sábido que a infecção natural é seguida pela rápida aparição de anticorpos nos indivíduos doentes, como foi demons. trado por Parkman, Buescher \& ARTENSTEIN ${ }^{14}$ (1962); Sever, Schiff \& Traub $^{22}$ (1962); Sigurdardottir et alii ${ }^{24}$ (1963); VERonelli; MAassab \& HENNESSY ${ }^{26}$ (1962); WeLler \& NeVA ${ }^{27}$ (1962); Green et alii ? (1965); Schiff et alii ${ }^{18}$ (1965) e Sever et alii ${ }^{23}$ (1966).

E conhecido também que êstes anticorpos persistem por muitos anos (KRUGMan \& Ward ${ }^{9}, 1958$; Schiff, Sever \& HuebNer ${ }^{17}, 1963$; Schiff et alii ${ }^{18}, 1965$ e Sever et alii ${ }^{23}, 1966$ ).
E finalmente aceito que a infecção por rubéola é seguida por uma imunidade para a vida tôda (ANDERson 1, 1949; Krugman et alii ${ }^{10}$, 1953; Sever et alii ${ }^{23}$, 1966; Plotkin, Cornfeld \& Ingalls ${ }^{16}$, 1965 e GREEN et alii ${ }^{7}, 1965$ ), muito embora alguns indiquem a possibilidade de reinfecção por rubéola, o que só seria possível de acontcer se a imunidade não fôsse duradoura (BRODY ${ }^{2}, 1966$ ).

Esta correlação entre ausência de anticorpos evidenciáveis pelas técnicas usuais. e suscetibilidade à infecção pelo vírus da rubéola foi referida por vários investigadores, ao observarem que indivíduos. que não apresentavam anticorpos eram suscetíveis à doença, enquanto que aquêles outros que possuiam anticorpos eram resistentes (SEvER, Schiff \& TRAUB ${ }^{22}$, 1962). GREEN et alii ${ }^{7}$ (1965) demonstraram conclusivamente êste fato, assinalando ainda que o título para separar indivíduos suscetíveis daquêles outros considerados imunes era o de 4 . Êstes autores observaram em 37 indivduos, por êles considerados imunes (título de anticorpos de 4 ou mais), que nenhum dêles adquiru a doença, enquanto que 46 dos 54 indivíduos por êles catalogados como suscetíveis contrairam rubéola.

Em face das observações comentadas anteriormente é que resolvemos iniciar as nossas determinações de níveis de anticorpos neutralizantes contra rubéola na diluição $1: 4$ e a partir desta continuar as diluições usando como fator 2 . Estas determinações nos forneceram os resultados consignados nas Tabelas 1 e 2 , nas quais pode ser verificado que das $778 \mathrm{mu}$ lheres grávidas participantes do nosso estudo, $22,88 \%$ não mostraram anticorpos nos seus soros e $77,12 \%$ apresentaram títulos de anticorpos distribuindo-se da seguinte forma: diluição $1: 4,23,26 \%$; $1: 8, \quad 20,57 \% ; 1,16,19,02 \% ; 1,32$, $7,71 \% ; 1: 64,1,41 \% ; 1: 128,2,83 \%$ e $1: 256,2,32 \%$; constatando-se que nas três primeiras diluições estão compreendidas $62,85 \%$ das gestantes. Os títulos por nós encontrados estão em concordân- 
COTILLO Z., L. G. - Anticorpos neutralizantes contra rubéola num grupo de gestantes de São Paulo. Rev. Saúde públ., 2(1):29-43, jun. 1968.

cia com os determinados por todos os au. tores de nosso conhecimento que abordaram o problema da determinação de níveis de anticorpos contra a rubéola.

Ao comparar os resultados obtidos no grupo de mulheres grávidas de São Paulo, com os apresentados por outros pesquisadores, verifica-se que no grupo de São Paulo, 77,12\% mostraram níveis de anticorpos e $22,88 \%$ não os apresentaram, enquanto que das 600 gestantes de um grupo de hospitais dos Estados Unidos (Sever, Schiff \& Huebner ${ }^{21}$, $1964)$, em $82,5 \%$ foram verificados niveis de anticorpos considerados protetores e $17,5 \%$ não os apresentaram. Na Inglaterra, OxFORD ${ }^{13}$ (1966) assinala igualmente para o grupo por êle estudado que aproximadamente $24 \%$ das mulheres grávidas não apresentaram anticorpos e Givan, Rozee \& Rhodes ; (1965), no Canadá, observaram a presença de $20 \%$ sem níveis de anticorpos neutralizantes.

Por outro lado, ao se contrastar os resultados obtidos neste trabalho com outros estudos, verifica-se que em mulheres índias e esquimós do Alaska em 1964 a percentagem de individuos sem anticorpos neutralizantes era de $18 \%$, muito próximo dos resultados apresentados no parágrafo anterior, enquanto que num grupo de 50 mulheres de Hawaii, estudado no mesmo ano, 44,4\% não apresentavam níveis de anticorpos (Sever, Schiff \& Huebner $\left.{ }^{21}, 1964\right)$. Outros grupos populacionais do mesmo Hawaii, referidos por SEver et alii ${ }^{23}$ (1965), dão para o Hospital Kaiser, de Honolulu, 58\% e para Hilo, $71 \%$ de gestantes sem anticorpos neutralizantes.

No sul do Japão a incidência observa. da de mulheres sem anticorpos foi de $34 \%$ e segundo os relatos preliminares referidos por SEVER ${ }^{19}$ (1967), a percentagem de mulheres sem título de anticorpos neutralizantes contra a rubéola nas Filipinas foi de 3\%; na Nigéria Oriental, 21\%; em Togo, 11\%; na Tailândia; $13 \%$ e na Tchescoslovaquia, $3 \%$.
Estas marcadas diferenças entre a incidência de mulheres sem anticorpos neutralizantes nas diversas comunidades, mostram a necessidade de se determinar os níveis de anticorpos em cada local, ainda que a comparação destas freqüências relativas seja muito grosseira, desde que se carece de dados referentes aos grupos etários integrantes de algumas das amostras, assim como da côr das mulheres participantes dêstes estudos, o que parece ter influência sôbre os níveis de anticorpos.

Consideramos que há um outro fator que pode estar influenciando esta grande variação dos resultados dos diversos pesquisadores que determinaram o nivel de anticorpos contra rubéola e que é o referente ao estado sócio-econômico. Acreditamos que a nossa amostra seja muito homogênea neste aspecto, uma vez que tôdas as gestantes participantes dêste estudo são pessoas que freqüentam hospitais beneficientes. Não existem maiores informaçōes sôbre êste particular nas observações dos diversos autores consignados neste trabalho.

A relação entre grupos etários e niveis de anticorpos contra a rubéola foi observada nos Estados Unidos por SEver, Schiff \& Huebner ${ }^{21}$ (1964), referindo que no grupo etário de 14 a 19 anos a freqüência de pacientes com anticorpos era de $74,8 \%$; no de 20 a 25 anos, $79,4 \%$; no de 26 a $30,86,2 \%$ e no de 31 a 44 anos, $89,1 \%$, assinalando que a frequiência de pacientes com níveis de anticorpos aumentava à medida que aumentavam as idades.

Posteriormente, outros pesquisadores estabeleceram os niveis de anticorpos para diversas populações e assim no $\mathrm{Ca}$ nadá, Givan, Rozee \& Rhodes ${ }^{5}$ (1965) observaram que na diluição $1: 6$, aos 14 anos, $60 \%$ apresentavam anticorpos, aos 19 anos, $70 \%$ e aos 24 anos, $80 \%$ e que nos grupos de acima de 24 anos esta proporção permanecia constante. Mas, ao fazer as mesmas determinações na diluição $1: 24$, observaram que os ní- 
COTILLO Z., L. G. - Anticorpos neutralizantes contra rubéola num grupo de gestantes de São Paulo. Rev. Saúde públ., 2(1):29-43, jun. 1968.

veis paralelos até os 19 anos, no grupo de 20 a 24 anos ia diminuindo até apresentar ùnicamente $20 \%$ de indivíduos com anticorpos neste nível no grupo de 35 a 40 anos.

Sever et alii ${ }^{23}$ (1965) em um estudo sorológico de 268 pessoas do Condado de Montgomery, Maryland, determinaram que a frequiência de anticorpos contra a rubéola aumentava de aproximadamente $35 \%$ no grupo de 1 a 10 anos até $85 \%$ em indivíduos de 16 a 25 anos. encontrando-se esta mesma percentagem também em grupos de mais idade.

OXFORD ${ }^{13}$ (1966) ao determinar os níveis de anticorpos neutralizantes contra rubéola em indivíduos de Sheffield, na Inglaterra, encontrou no grupo de I a 4 anos, 21,4\% de soros com anticorpos nas diluiçôes de $1: 8$ e maiores; no grupo etário de 5 a 10 anos, $66,1 \%$ nas mesmas diluições; no grupo de 12 a 16 anos, $68,1 \%$; de 16 a 25 anos, $76,5 \%$; de 26 a 40 anos, $76.6 \%$ e de 60 a 86 anos, $49,2 \%$ de indivíduos com anticorpos neutralizantes. É de se fazer notar que a amostra estava integrada por mulheres grávidas nos grupos de 16 a 25 anos e de 26 a 40 anos.

Quando o mesmo autor considerou ùnicamente os indivíduos cujos soros apresentavam anticorpos nas diluiçôes de 1:40 ou mais a variação percentual foi, para o grupo de 1 a 4 anos, 2,4\%; de 5 a 10 anos, $42.8 \%$; de 12 a $16,21.6 \%$; de 16 a $25,35,3 \%$; de 26 a $40,17 \%$ e de 60 a 86 anos, $13,8 \%$ de indivíduos com anticorpos nessas diluições.

No presente trabalho, os resultados encontrados nas determinaçóes de anticorpos nos soros das 778 gestantes, com uma idade média de 25,6 anos, permitem verificar que no grupo etário de 15 a 19 anos a freqüência de pacientes com anticorpos nas diluições de $1: 4$ ou mais era de $79,43 \%$; no grupo de 20 a 24 anos, $75,69 \%$; no de 25 a $29,77,38 \%$; de 30 a 34, 82,50\%; de 35 a 39 , $75.68 \%$ e de 40 a $44,44,50 \%$.
A comparação dos resultados obtidos em cada grupo etário da amostra examinada, nos permite verificar que os percentuais das idades compreendidas entre 15 a 39 anos são muito próximas, sendo que o grupo de 40 a 44 anos apresenta um percentual notadamente menor de pacientes com anticorpos. Esta discordância demonstrou-se estatisticamente significativa ao nível de 0,01 (GOLD ${ }^{6}, 1962$ ).

Entretanto, o pequeno número de indivíduos integrantes dêste grupo etário de 40 a 44 anos, faz-nos sentir a necessidade de se ampliar os estudos sôbre nível de anticorpos nestes grupos de mais idade, a fim de se confirmar ou não esta discordância e tentar determinar as causas que originam esta diminuição dos níveis de anticorpos neutralizantes.

Ao examinar cada um dos grupos etários em relação aos níveis de anticorpos. podemos observar que a maioria das gestantes de cada um dêstes grupos apresenta títulos de $1: 4$ e $1: 8$, o que concorda com os resultados encontrados por outros pesquisadores, oferecendo a possibilidade de ser a resposta imunitária não muito intensa à infecção provocada pelo vírus da rubéola ou da pouca sensibilidade dos métodos empregados na sua determinação.

Ao considerarmos a relação dos grupos etários com os níveis de anticorpos neutralizantes, pode ser verificado que no grupo de gestantes de São Paulo, com idades de 15 a 19 anos, a percentagem de indivíduos com anticorpos foi de $79,43 \%$, enquanto que para um grupó de mulheres grávidas do território continental dos Estados Unidos, com idades de 14 a 19 anos, a mesma percentagem foi de $74,8 \%$ (Sever, Schiff \& HuebNER $\left.{ }^{21}, 1964\right)$.

Para o grupo de 20 a 24 anos, o nosso estudo obteve como resultados, 75,69\% de indivíduos com nível de anticorpos e o dos Estados Unidos, para o grupo de 20 a 25 anos, encontrou $79,4 \%$. A diferença é mais marcante ao se confron- 
COTILLO Z., L. G. - Anticorpos neutralizantes contra rubéola num grupo de gestantes de São Paulo. Rev. Saúde públ., 2(1):29-43, jun. 1968.

tarem os resultados obtidos em São Paulo para o grupo de 25 a 29 anos, que apresentou $77,3 \%$ de gestantes com anticorpos, uma vez que para um grupo se. melhante de 26 a 30 anos, nos Estados Unidos foi observado um percentual de $86,2 \%$ de mulheres com anticorpos.

A diferença se acentua muito mais ao se compararem os resultados dêstes dois estudos para os grupos etários de 30 a 44 anos que, em São Paulo mostra 77,1\% de indivíduos com anticorpos, enquanto que nos Estados Unidos o grupo de 31 a 44 anos apresentou $89,1 \%$ de gestan tes com anticorpos.

Ao relacionar os resultados obtidos neste trabalho com os apresentados nas mulheres grávidas de Sheffield referidos por OxFord ${ }^{13}$ (1966), verificamos que no grupo de 15 a 24 anos, $77 \%$ apresentam anticorpos na nossa amostra, enquanto que no grupo de 16 a 25 anos do estudo realizado na Inglaterra, 76,5\% mostraram níveis de anticorpos. No grupo de 25 a 39 anos, as gestantes de São Paulo apresentaram $78,7 \%$ de indivíduos com anticorpos neutralizantes $\mathrm{e}$ as da Inglaterra, do grupo de 26 a 40 anos, $76,6 \%$.

É de se fazer notar que os grupos etários, embora muito próximos, não foram exatamente iguais.

Sever, Schiff \& Huebner ${ }^{21}$ (1964) analisaram a freqüência de anticorpos em mulheres grávidas com relação a côr nos Estados Unidos. Das 600 mulheres grávidas por êles examinadas, "241 eram de côr branca, 292 de côr preta e 67 porto-riquenhas". A idade média de cada um dêstes três grupos foi de 25,9 anos, 25,3 anos e 25,6 anos, respectivamente. Assinalaram que das gestantes brancas, $86,3 \%$ apresentavam anticorpos; das mulheres grávidas de côr preta, $79,4 \%$ mostravam nos seus soros títulos de anticorpos e nas porto-riquenhas, $82 \%$ possuiam nível de anticorpos. Esta diferença foi estatisticamente significativa ao nível de $\leq 0,05$ para os anticorpos neutralizantes contra rubéola apresenta- dos nas populações de gestantes de côr branca e gestantes de côr preta. Êles assinalaram igualmente que os fatôres responsáveis por essa mais alta freqüência de indivíduos sem anticorpos neutralizantes ao serem comparados com as gestantes de côr branca, não puderam ser esclarecidos.

$\mathrm{Na}$ amostra por nós estudada, das 350 gestantes de côr branca, com uma idade média de 25 anos, $79,14 \%$ apresentaram anticorpos; das 90 pacientes de côr preta, com idade média de 26,1 anos, $75.56 \%$ possuiam anticorpos; das 317 mulheres grávidas de côr parda, com idade média de 26,1 anos, $75,71 \%$ mostravam niveis de anticorpos e das 21 gestantes de côr amarela, com idade média de 29,1 anos, $71,43 \%$ possuiam níveis de anticorpos.

Estas frequiências relativas ao serem submetidas ao tratamento estatístico mostraram-se não significativas ao nível de 0,01 . Isto discorda dos resultados de Sever, Schiff \& Huebner ${ }^{21}$ (1964). que encontraram diferenças significativas entre as gestantes de côr branca e as de côr preta. Em todo caso, não se pode deixar de observar que as pacientes de côr amarela foram as que apresentaram a menor freqüência relativa, embora a amostra fôsse de número muito pequeno, e as mulheres grávidas de côr preta e parda apresentaram percentuais quase totalmente idênticos, diferindo da freqüência relativa observada nas gestantes brancas.

Esta diferença por nós encontrada pode ser atribuída ao fato de não serem êstes quatro grupos homogêneos em relação à idade, uma vez que constatamos que as gestantes de côr amarela apresentaram idade média mais alta que os outros grupos, conforme pode ser verificado na Tabela 4. Ao mesmo tempo, as gestantes de côr branca foram as que mostraram a menor idade média.

Por outro lado, parece ser necessária a determinação das respostas imunitárias em cada comunidade para se verifi- 
COTILLO Z., L. G. - Anticorpos neutralizantes contra rubéola num grupe de gestantes de São Paulo. Rev. Saúde públ., 2(1):29-43, jun. 1968.

car se êste fato, de diferente suscetibilidade à ação do vírus da rubéola, guarda relação com a côr; ou se depende de algum fator ainda não estabelecido, uma vez que todos os estudos anteriormente relatados ao abordar êste problema mostraram resultados discordantes.

Um fato que desperta a atenção é o encontrado na Tabela 4 ao examinar o grupo integrado pelas gestantes de côr amarela. Verifica-se que no nível de $1: 4$, estão $9,52 \%$ das gestantes dêste grupo; no nível de $1: 8,23,81 \%$; no de $1: 16,23,81 \%$; no de $1: 32,9,52 \%$ e no de $1: 128,4,77 \%$. Embora êste grupo fôsse muito pequeno, não permitindo, portanto, chegar a afirmações conclusivas, parece que a presença de poucos indivíduos com níveis altos de anticorpos neutralizantes, indicaria diferença de suscetibilidade em relação ao vírus ou eliminação mais acelerada dos anticorpos protetores, nas gestantes desta côr.

\section{CONCLUSOES}

As observações apresentadas anteriormente permitem indicar algumas conclusões no que se refere ao estado imunitário contra a rubéola na população estudada, assim como sôbre os métodos utilizados na sua determinação.

1. Em inquéritos epidemiológicos de larga escala, a prova de sôro-neutralização apresenta inconvenientes de ordem prática pelo que se faz necessário estudar mais amplamente a correlação dos resultados desta técnica com aquêles fornecidos por outras, entre as quais se destaca, sem dúvida, a reação de inibição da hemaglutinação.

2. A amostra estudada no presente trabalho, representativa da população que freqüenta a Casa Maternal Leonor Mendes de Barros, apresenta características de homogeneidade no que se refere ao aspecto sócio-econômico.
3. No grupo estudado, a presença de $22,88 \%$ de gestantes desprovidas de anticorpos neutralizantes em nível considerado protetor, permitiria indicar que em tôda a população de nível sócio-econômico semelhante, residente no município de São Paulo, deverá existir número de indivíduos suscetíveis à doença suficiente para que exista a probabilidade de se apresentar elevado número de casos nos próximos anos.

4. Nos cinco grupos etários compreendidos entre 15 a 39 anos foram reveladas freqüências aproximadamente iguais de mulheres grávidas sem anticorpos, elevando-se notadamente no grupo etário de 40 a 44 anos. Isto faz com que recomendemos um estudo mais aprofundado dos níveis de anticorpos nos grupos etários acima de 40 anos.

5. As gestantes de côr branca pareceriam ser mais suscetíveis à infecção pelo vírus da rubéola, verificando-se que a menor prevalência estaria no grupo de mulheres grávidas de côr amarela. No entanto, estas diferenças não foram estatìsticamente significativas, ainda que estudos apresentados por outros autores tenham revelado valores significativos no que se refere a suscetibilidade à rubéola em relação à côr.

6. É preciso realizar determinações dos níveis de anticorpos contra a rubéola em amostras representativas de tôdas as idades dos habitantes do município de São Paulo, para se conhecer a realidade sôbre $\cdot a$ incidência da infecção nesta localidade, assim como determinar a necessidade ou não de vacinação nos grupos expostos ao maior risco pelas infecções à rubéola, isto é, as gestantes quando no primeiro trimestre da gravidez.

\section{S U M M A R Y}

Levels of neutralizing antibodies against rubella were determined on 778 pregnant 
COTILIO Z., L. G. - Anticorpos neutralizantes contra rubéola num grupo de gestantes de São Paulo. Rev. Saúde públ., 2(1):29-43, jun. 1968.

women attending the Outpatient Department of the "Casa Maternal Leonor Mendes de Barros". Of the 778 women, 600 had titers of 4 and over (dilution $1: 4)$. The total group presented an average age of 25.6 years. For the 15 to 19 years group, $79.43 \%$ of the patients had titers of 4 and over; in the remaining groups the corresponding percentages were: 20 to 24 years, $75.69 \% ; 25$ to 29 years, $77.38 \%$; 30 to 34 years, $82,50 \%$; 35 to 39 years, $74.58 \%$ and 40 to 44 years, $50.00 \%$. Comparison of these results shows that percentages of positivity at ages between 15 and 39 years are very similar but those of group 40 to 44 years are markedly lower. The difference is statistically significant at the level of 0.01 . Regarding the color, $79.14 \%$ of the 350 white females, $75.56 \%$ of the 90 negro females, $75.71 \%$ of the 317 halfbreeds and $71.43 \%$ of the 21 yellow females (japanese) showed antibodies at the above mentioned level. For epidemiologic surveys, on large scale, the neutralization test presents certain practical disadvantages, which renders ample study of correlation of the results of this test with those of other tests (among which haemagglutination inhilition test stands out ) necessary.

\section{A GR A DECIM EN T OS}

Queremos vir a público agradecer ao Prof. Dacio de Almeida Christovão, Professor da Cátedra de Microbiologia Aplicada da Faculdade de Higiene e Saúde Pública da USP; ao Professor Domingos Delascio, da Casa Maternal Leonor Mendes de Barros; ao Professor J. A. Dudgeon, do "The Hospital for the Sick Children" de Londres e ao Departamento de Estatística Aplicada da Faculdade de Higiene e Saúde Pública, através da Dra. Maria Lucila Milanesi, Dra. Eunice Pinho de Castro Silva e Dr. José Maria Pacheco de Souza.

\section{REFERENCIAS BIBLIOGRAICAS}

1. ANDERSON, S. G. - Experimental rubella in human volunteers. J. Immunol., 62(1) : 29-40, May, 1949.

2. BRODY, J. A. - The infectiousness of rubella and the possibility of reinfection. Amer. J. publ. Hlth, 56(7):10821087, July, 1966.

3. CHANG, R. S. \& GEYER, R. P. - A serum albumin medium for the cultivation of human epithelial like cells. J. Immunol., 79(6):455-461, Dec, 1957.

4. DUdGEON, J. A.; BUTLER, N. R. \& PLOTKIN, S. A. - Further serological studies on the rubella syndrome Brit. med. J., 2(5402):155-160, July, 1964.

5. GIVAN, K. F.; ROZEE, R. K. \& RHODES, A. J. - Incidence of rubella antibodies in females subjects. Canad. med. Ass. J., 92(3):126-128, Jan. 1965.

6. GOLD, R. Z. - On comparing multinomial probabilities. Brooks (Tex.) School of Aerospace Medicine, 1962.

7. GREEN, R. H. et alii - Studies of the natural history and prevention of rubella. Amer. J. Dis. Child., 110(4): 348-365, Oct. 1965.

8. HUTCHINSON, D. N. \& THOMPSON, K. M. - Continuous rabbit kidney cell cultures in the diagnosis of rubella infections. Mth. Bull. Minist. Hlth Lab. Serv., 24:385-391, Dec. 1965.

9. KRUGMAN, S. \& WARD, R. - Rubella: demonstration of neutralizing antibody in gamma globulin and re-evaluation of the rubella problem. New Engl. J. Med., 259:16-19, July, 1958.

10. KRUGMAN, $\mathrm{s}$. et alii - Studies on rubella immunization. I. Demonstration of rubella without rash. J. Amer. med. Assoc., 151(4):285-288, Jan. 1953.

11. LEERHOY, J. - The influence of ditferent media on cell morphology and rubella virus titer in a rabbit cornea cell line (SIRC). Archiv. ges. Virusforschung, 19:210-214, 1966.

12. MCCARTHY, K.; TAYLOR-ROBINSON, C. H. \& PILLINGER, S. E. - Isolation of rubella virus from cases in Britain. Lancet, 2(7308): 593-601, Sept. 1963. 
COTiLlo z., L. G. - Anticorpos neutralizantes contra rubéola num grupo de gestantes de São Paulo. Rev. Saúde públ., 2(1):29-43, jun. 1968.

13. OXFORD, J. -- Rubella, virus- 1966 . Publ. Flth, 80(6):271-276, Sept. 1966.

14. PARKMAN, P. D.; BUESCHER, E. L. \& ARTENSTEIN, M. S. - Recovery of rubella virus from army recruit. Proc. Soc. exp. Biol., N. Y., 111(1):225-230, Oct. 1962.

15. et alii — Studies of rubella. II. Neutralization of the virus. $J$. Immunol., 93(4):608-617, Oct. 1964.

16. PLOTKIN, S. A.; CORNFELD, D. \& INGALLS, T. H. - Studies on immunization with living rubella virus. Amer. J. Dis. Child., 110(4):381-389, Oct. 1965.

17. SCHIFF, G. M.; SEVER, J. L \& HUEBNER, $\mathbf{R}$ J. - Rubella virus: neutralizing antibody in comercial gamma globulin. Science, 142(3588):58-60, Oct. 1963.

18. __ et alii — Rubella: studies on the natural disease: the significance ... antibody status and communicability among young women. Amer. $J$. Dis. Child., 110(4):366-369, Oct. 1965.

19. SEVER, J. L. - Epidemiology of rubella. In: International Conference on Vaccines against Viral and Rickettsial Diseases of Man, 1st, Washington, D.C., 1966. Washington, D.C., P.A.H.O., 1967. p 366-370 (Scientific publication, 147).

20. ; NELSON, K. B. \& GILKENSON, M. R. - Rubella epidemic, 1964: effect on 6,000 pregnancies. I. Preliminary clinical and laboratory findings througth the neo-natal period: a report from the collaborative study on cerebral palsy. Amer. J. Dis. Child., 110 (4) :395-407, Oct. 1965.
21. — SCHIFF, G. M. \& HUEBNER, R. J. - Frequency of rubella antibody among pregnant women and other human and animal populations. Obstet, and Gynec., 23(2):153-159, Feb. 1964.

22. ; SCHIFF, G. M. \& TRAUB, R. G. - Rubella virus. J. Amer. med. Assoc, 182(6):663-671, Nov. 1962.

23. _- et alii - Antibody responses in acute and chronic rubella. Proc. Soc. exp. Biol. Med., N. Y., 122(2):513-516, June, 1966.

24. SIGURDARDOTTTIR, B. et alii - Association of virus with cases of rubella studied in Toronto: propagation of the agent and transmission to monkeys. Canad, Med. Ass. J., 88(3):128-132, Jan. 1963.

25. STEWART, G. L. et alii - Rubella virus hemaglutination inhibition test. New Engl. J. Med., 276(10):554-557, Mar. 1967.

26. VERONELLI, J. A.; MAASSAB, H. F. \& HENNESSY, A. V. - Isolation in tissue culture of an interfering agent from patients with rubella. Proc. Soe. exp. Biol. Med., N. Y., 111(2):472-476, Nov. 1962

27. WEller, T. H. \& NEVA, F. A. - Propagtion in tissue culture of cytopathic agents from patients with rubella like illness. Proc. Soc. exp. Biol., N.Y., 111 (1) :215-225, Oct. 1962 .

28. — \&EVA, F A. - Rubeila virus. In HORSFALL, F. L. \& TAMM, I. - Viral and rickettsial infections of man. 4th ed. Philadelphia, Lippincott, 1965. p. 802-809. 